\title{
Stereo-Photo Surveying: Discussion
}

Author(s): David Gill, Major Hills, Mr. Conrady and Major Close

Source: The Geographical Journal, Vol. 31, No. 5 (May, 1908), pp. 549-551

Published by: geographicalj

Stable URL: http://www.jstor.org/stable/1777501

Accessed: 25-06-2016 17:23 UTC

Your use of the JSTOR archive indicates your acceptance of the Terms \& Conditions of Use, available at

http://about.jstor.org/terms

JSTOR is a not-for-profit service that helps scholars, researchers, and students discover, use, and build upon a wide range of content in a trusted digital archive. We use information technology and tools to increase productivity and facilitate new forms of scholarship. For more information about JSTOR, please contact support@jstor.org.

The Royal Geographical Society (with the Institute of British Geographers), Wiley are collaborating with JSTOR to digitize, preserve and extend access to The Geographical Journal 


\section{The Plotting.}

The nature of the country, the scale of the map, the vertical interval of the contours, will determine the number of points to be fixed per square mile. Under average conditions, it may be taken to vary from 50 to 200. For economical work, a plotting machine should be able to keep pace with a camera party; that is to say, it should be capable of fixing in plan and altitude from 500 to 2000 points per diem.

By the Canadian method of intersections, twenty-five points plotted by at least three rays is considered a good day's work.*

Mr. Fourcade's instrument, which works on similar lines to Dr. Pulfrich's stereo-comparator, gives twenty-five points per hour in the hands of an observer who has had no practice. $\dagger$

The stereo-plotter was designed with a view to increasing the speed of plotting. It has been found that with this instrument from 100 to 150 points per hour can be fixed. The present instrument is an experimental one only, and admits of several improvements which would increase the speed of plotting and its accuracy.

The procedure adopted in plotting was as follows. The triangulation stations lettered, and the resected camera stations numbered, were carefully marked on a large sheet of tracing cloth. Each piece of plotting when completed was then placed beneath the tracing and oriented by means of two fixed points, or one point and an azimuth. The detail was then traced on the tracing cloth.

In this way the map was built up, and very little adjustment was found necessary where the different portions net.

The rate of plotting of the Cumberland survey' was approximately 8 square miles per diem, the rate of field work was 10 square miles per diem. From 40 to 70 points per square mile were plotted. In considering these figures it must be remembered that this was a first attempt, and executed with more or less improvised instruments. The advance made, however, is encouraging, and I am now considering the design of an improved plotting machine, or "stereo-planigraph," which will be entirely automatic, and in which contours can be traced direct on the plotting sheet without any reference to scales or settings, and without moving the eyes from the eye-pieces of the stereoscope. Preliminary drawings have been shown to $\mathrm{Mr}$. Conrady, whose expert advice throughout has been of the greatest assistance. He is of opinion that the construction of the instrument offers no insurmountable difficulties. The increase in speed and accuracy of plotting should be very considerable. $\$$

After the paper, Sir DAVID GILL: I note with very great interest that with observations by stereoscopic methods you get twice the amount of precision that you do from measurements depending upon angles at right angles to the line of sight. That was Prof. Forbes's experience. He said that with his little balloon with the rope hanging down (which corresponds with the bottle-shaped figure in this apparatus), he found he could get the appreciation of parallactic displacement twice as accurately by the stereoscopic method as he could by the

- Vide 'An Elementary Treatise on Phototopographic Methods.' By J. A. Flemer.

† Journal of the Institute of Land Surveyors of the Transvaal, vol. 1, No. 6.

I Since writing the above, funds have been allotted by the Royal Engineer Committee for the construction of a new light camera equipment and an improved stereoplotter. Experiments will probably be carried out with these instruments in the course of the summer. 
method of measurement at right angles to the line of sight. With regard to the details of this instrument as described in this paper which was kindly sent us in advance, I venture to suggest that it might be a very good thing if an appendix to the paper could be given written from a technical point of view, describing more perfectly and technically and without fear of an algebraic expression exactly what it is the author bas done, and desires us above all to understand. The only objection I find to this method of plotting coordinates is that you do not get the full advantage by that method of the magnifying power which you apply in reading the negatives or positives from it. The mechanical translation from the instrument to paper necessarily involves some loss of accuracy, and of course, if one wanted really, with a 6 -inch focus, to get the utmost that could be got from the instrument, you would use a much larger measuring apparatus, and magnify the original photographs so as to diminish the mechanical errors of the reproduction. I might remark that the estimated error of $\frac{1}{400}$ in the measuring of the base by an'. invar wire is a most extravagantly large one, because you can, without the very least difficulty, measure to $\frac{1}{100 \overline{0}}$, and with all possible precaution to $\overline{1} \overline{0} \overline{1} \overline{0} \overline{0} \overline{0}$.

Major Hills : I should like to say a few words, perhaps in the first instance somewhat in the nature of a personal recantation, because I have been rather sceptical about photographic methods of surveying, and some time ago, when I first heard of the stereoscopic method, I was not inclined to believe in it. I must, however, say that after seeing how the work is done and how simple the operations are, I am completely converted to the photographic method as applied in this particular development of it. The principal difficulty of photographic surveying in the past has been the identification of points as seen from different stations. That difficulty is not only got over here, but I may say rather more than got over, because I think it is actually easier to identify points in these photographs than on the ground.

Another salient advantage of this method is the rapidity of the plotting, and consequently the old objection to photographic surveying, viz. its extreme slowness compared with plane-tabling, disappears. This can be further accelerated if two men are employed, one to set the microscopes, and one to draw. I think this stereoscopic method, combined with a plotting machine, as shown us this afternoon, has a very large future before it.

Mr. CoNRADY said that in his opinion the accuracy of the map produced on the instrument did not depend upon the mechanical transmission of the direction and height to any great extent. The parallax, on which the distance of the various points depended, was a very small quantity, and it was the accuracy attained in the measurement of this by a coarse screw that put a limit to the precision attainable by the instrument. If speed in working were sacrificed a fine micrometer screw might be substituted for the measurement of the parallax, and the accuracy of the resulting $\mathrm{r}$ s.p would be increased without sacrificing the mechanical transmission of two of the co-ordinates.

Major Close : Before thanking Mr. Thompson for his lecture, I should like to say that Mr. Reeves * will give us a demonstration of his new distance finder, and I think it would be better if we had that paper first; then we could get round the instruments and examine them afterwards. As regards the paper we have just listened to, I think myself that the method is certainly bound to come in for future local exploration, but I do not think it is likely to be adopted for exact and extended surveys for a very long time. I do not think you have got the accuracy

* See Geographical Journal for April, 
necessary, and it has the fundamental defect that you do not walk over the ground; and also there is this difficulty, that in wooded country and in flat country you really cannot use it at all. But I think it should undoubtedly be adopted by people who are engaged in exploring mountainous regions which are difficult to get at, or in the ordinary explorer's work where a man may very likely camp for a week or two in a place, where he can take the photographs; after he comes home these can be developed and a regular map produced-something very much better than the explorers bring home now. There is one other point I should mention. I think I may say, on behalf of the Research Department, that we do not mind how technical a subject is. This time we ought certainly to have an appendix to the paper, an appendix which will give the more technical side, which has been omitted in the paper which was circulated. On your behalf I beg to thank Mr. Thompson for his exceptionally interesting paper.

\section{REVIEWS. EUROPE.}

France.

'La France.' By Vidal de la Blache, Membre de l'Institut. With 302 engravings and maps in the text, and a separate coloured map. Paris: Hachette. 1908 [1907]. Price $25 \mathrm{fr}$.

THIs admirable and indeed model geographical work, model in point of style as well as of geographical interest, was reviewed on its original publication on p. 112 of vol. 23 of the Journal. It has now been converted into a hand some quarto volume, with wide margins and numerous pictorial illustrations, which add to its geographical value; for these views are all carefully selected to illustrate distinctive geographical features, and all have notes appended to set forth their geographical significance. The only complaint that can be made is that these notes are in a type rather too small, and, on the glossy paper, rather too faint to be easily read, especially where the lines run across the whole width of the page, and are thus not very easy to follow.

G. G. C.

\section{ASIA.}

\section{BURma.}

'The Province of Burma.' By Alleyne Ireland. Boston and New York:

Houghton \& Mifflin. Two vols. Pp. xxi., 1023. 2 Maps. Price $\$ 10$.

These two massive volumes are the first instalment of the Report on Colonial Administration in the Far East, for the preparation of which $\mathrm{Mr}$. Ireland received the appointment of Colonial Commissioner of Chicago University in 1901. In a general preface he acknowledges the very full assistance, both official and unofficial, which he has received in the prosecution of his work, and these two volumes alone are sufficient evidence of the careful use he has made of it. He premises that no attempt has been made to render the volumes attractive to the general reader, but no reader could fail to appreciate the admirable arrangement of the volumes considered as works of reference; the only possible criticism in this connection appears to be that, in view of the full analysis of each chapter given in the contents table, the index might, perhaps, to a greater extent than it does, have given each detail in its own alphabetical place, instead of grouping details under general headings, or 